\title{
Intelligence, consistency, and Emerson's dilemma
}

Kimmo Sorjonen $^{1}$, Tomas Hemmingsson
\& ${ }^{2,3}$,

${ }^{1}$ Department of Clinical Neuroscience, Karolinska Institutet, Stockholm, Sweden

2 Department of Public Health Sciences, Stockholm University, Stockholm, Sweden

${ }^{3}$ Institute of Environmental Medicine, Karolinska Institutet, Stockholm, Sweden

In a large representative sample of Swedish male conscripts $(N=49,246)$, we demonstrate a positive association between intelligence and response consistency on items measuring endorsement of a strong military defense. This association is accentuated, to some degree, by an apparent difficulty to handle reversed items among those with low intelligence. Consequently, due to regression toward the mean, reversed items in measurement instruments would tend to have a negative effect on statistical power when analyzing the association between whatever the instrument is measuring and intelligence. On the other hand, the presence of reversed items could mitigate bias in the measurement due to an acquiescent response style among those with low intelligence. Lack of motivation/carelessness and inadequate reading ability among some subjects are two possible confounders for the found association in the present study.

Key words: intelligence; Ralph Waldo Emerson; response consistency; reversed items.

\section{Introduction}

On self-report measures, response consistency has been found to be lower, for example, among younger compared to older children (Meijer, Egberink, Emons \& Sijtsma, 2008), among those experiencing negative affectivity (Reise \& Waller, 1993), and those with lower education (McFarland \& Sparks, 1985) and higher degree of PTSD symptoms (Conijn, Emons, van Assen, Pedersen \& Sijtsma, 2013). Studies have also indicated that high intelligence is associated with less extreme response patterns (Light, Zax \& Gardiner, 1965; Makowsky \& Miller, 2014; Wilkinson, 1970).

Furthermore, a positive association between intelligence and response consistency has been found for measures of youth delinquency (Pinsoneault, 1998), measures of aggression, impulsivity, psychological maturity, and callousness (Navarro-González, Ferrando, \& Vigil-Colet, 2018), and measures of the Big Five personality traits (Allik, Laidra, Realo, \& Pullmann, 2004; Austin, Deary, \& Gibson, 1997; Escorial, NavarroGonzález, Ferrando, \& Vigil-Colet, 2019). It has been suggested that such association between intelligence and consistency might be due to, for example, poorer understanding of questionnaire items but also due to a lower degree of traitedness among those with lower ability (Austin et al., 1997; Brand, Egan, \& Deary, 1994).

The objective of the present study was to investigate if the association between intelligence and response consistency extends to measures of opinion and if it is affected by the inclusion of reversed items.

\section{Method}

\section{Ethics statement}

The Stockholm Regional Ethical Review Board has in decisions according to minutes 2004/5:9 agreed to co-processing of the compulsory military service material. The inclusion of more recent data to the database has also been approved by the Review Board (Dnr 2008/323-32 and 2010/604-32). We have had at our disposal only non-identifying information. Due to the character of the data base and the anonymization of all data, the Review Board waived the normal requirement for written consent.

\section{Subjects}

The present study was based on data from 49,246 Swedish males, born between 1949 and 1951. They were conscripted for compulsory military service in $1969 / 70$. At that time, only 2-3\% of all Swedish men were exempted from conscription, in most cases owing to severe handicaps or congenital disorders.

\section{Assessment of intelligence}

Four separate intelligence tests were performed, mainly in order to assess the conscripts' suitability for education as officers (Ross, 1988). (1) In a test named Instructions, the conscripts were required to follow written instructions, e.g. "cross over the second number and encircle the number 4 ". This test had a time limit of 12 minutes and consisted of 40 questions; (2) In a test named Selection, the conscripts had to mark the odd one out of five words. This test had a time limit of 7 minutes and consisted of 40 questions; (3) In a test named Assembly, the conscripts had to determine which of four groups of pieces could be arranged to match a given figure. This test had a time limit of 4 minutes and consisted of 25 questions; (4) A last test, named Technical understanding, consisted of diagrams requiring mechanical ability. This test had a time limit of 15 minutes and consisted of 52 questions (Ross, 1988). According to Ross (1988), Instructions and Selection measured logical inductive and verbal intelligence, while Assembly measured spatial intelligence, and Technical understanding measured technical understanding. All the tests were progressive, starting with relatively simple questions that gradually became more difficult (Carlstedt, 2000; 
Hemmingsson, Melin, Allebeck, \& Lundberg, 2006; Zammit et al., 2004). The raw scores on all four tests were standardized to a scale from one to nine by the conscription personnel who then summed these four scores and standardized it to a normally distributed total intelligence test score ranging from one to nine (Ross, 1988; Carlstedt, 2000).

\section{Response items}

On scales from 0 (= absolutely not) to 4 (= absolutely yes) the conscripts rated their opinion on the following statements (translated from Swedish) (1) Do you think that a strong Swedish military defense will increase our chances to stay out of an eventual war? (2) Do you think that we should engage in armed resistance if Sweden gets attacked even if the outcome seems uncertain? (3) If an aggressor threatens with nuclear weapons, do you think that we should engage in armed resistance? (4) If an aggressor threatens with nuclear weapons, and we have such weapons ourselves, do you think that we should use them? (5) Do you think it would promote world peace if Sweden disarmed on its own? (6) Do you think it is proper that in Sweden citizens are required to defend their country with weapons? On all items except 5, which is reversed, a high value indicates endorsement of a strong military defense. It should be emphasized that the main objective of the present study was not to measure the association between intelligence and opinions about a strong military defense per se, but rather to use these items to measure response consistency.

\section{Statistical analyses}

Coefficient alpha was used as a measure of response consistency. A high alpha-value (upper bound $=1$ ) is taken to indicate that a large proportion of the test variance is due to common factors among test items rather than item specific factors (Cronbach, 1951; Guttman, 1945). However, coefficient alpha tends to underestimate reliability, especially when the assumption of tau equivalence (= the true score of each item has an equally strong loading on the true total score) is violated (Lord \& Novick, 1968; McNeish, 2018; Raykov, 1997; Sijtsma, 2009). Therefore, we also calculated coefficient omega (McDonald, 1999), which has been indicated as a more accurate measure of reliability compared to coefficient alpha in many situations (McNeish, 2018; Revelle \& Zinbarg, 2009).

The subjects' score on a scale measuring endorsement of a strong military defense was calculated in three different ways: (1) individual means on the standardized items; (2) factor scores from a factor analysis requesting a single factor; (3) theta $(\theta)$ values from an analysis with partial credit model (PCM). According to Rasch's (1960) dichotomous response model, the probability of subject $i$ to respond correctly on a dichotomous item $j\left(X_{i j}=1\right)$ is a function of the subject's ability $\left(\theta_{i}\right)$ and the difficulty of the item $\left(b_{j}\right)$ :

$$
P\left(X_{i j}=1\right)=\frac{e^{\theta_{i}-b_{j}}}{1+e^{\theta_{i}-b_{j}}}
$$

The values for parameters $\theta$ and $b$ are calculated so as to maximize the fit between predicted and observed responses. PCM is a generalization of Rasch's dichotomous response model that can be used with ordered polytomous items. On a Likert scale from 1 (= strongly disagree) to 5 (= strongly agree), for example, the probability of each step on

Table 1. Means $(S D)$ for the six items for all subjects as well as separately for the nine levels of intelligence (upper part). Correlations between the six items as well as with intelligence (bottom part).

\begin{tabular}{ccccccc}
\hline Intell. & item 1 & item 2 & item 3 & item 4 & item 5 $^{\text {a }}$ & item 6 \\
\hline All & $2.13(1.26)$ & $2.64(1.23)$ & $1.69(1.33)$ & $1.98(1.38)$ & $1.43(1.12)$ & $2.63(1.19)$ \\
1 & $2.35(1.14)$ & $2.58(1.10)$ & $2.24(1.26)$ & $2.47(1.19)$ & $1.92(1.03)$ & $2.76(1.09)$ \\
2 & $2.24(1.12)$ & $2.68(1.07)$ & $2.05(1.24)$ & $2.35(1.20)$ & $1.72(0.97)$ & $2.76(1.01)$ \\
3 & $2.15(1.16)$ & $2.66(1.10)$ & $1.89(1.26)$ & $2.25(1.25)$ & $1.59(0.98)$ & $2.71(1.05)$ \\
4 & $2.10(1.18)$ & $2.68(1.15)$ & $1.78(1.29)$ & $2.15(1.32)$ & $1.47(1.01)$ & $2.70(1.10)$ \\
5 & $2.07(1.22)$ & $2.66(1.19)$ & $1.65(1.29)$ & $2.00(1.35)$ & $1.42(1.07)$ & $2.64(1.14)$ \\
6 & $2.09(1.27)$ & $2.63(1.25)$ & $1.57(1.33)$ & $1.87(1.39)$ & $1.35(1.12)$ & $2.61(1.20)$ \\
7 & $2.11(1.34)$ & $2.62(1.31)$ & $1.55(1.34)$ & $1.77(1.43)$ & $1.31(1.19)$ & $2.58(1.27)$ \\
8 & $2.18(1.36)$ & $2.62(1.35)$ & $1.56(1.40)$ & $1.73(1.47)$ & $1.30(1.24)$ & $2.57(1.31)$ \\
9 & $2.19(1.38)$ & $2.57(1.39)$ & $1.60(1.40)$ & $1.68(1.48)$ & $1.35(1.30)$ & $2.48(1.37)$
\end{tabular}

\begin{tabular}{lrrrrrr} 
item2 & $.570^{*}$ & & & & \\
item3 & $.416^{*}$ & $.534^{*}$ & & & \\
item4 & $.389^{*}$ & $.516^{*}$ & $.633^{*}$ & & \\
item5 & $-.403^{*}$ & $-.470^{*}$ & $-.266^{*}$ & $-.304^{*}$ & & \\
item6 & $.573^{*}$ & $.658^{*}$ & $.437^{*}$ & $.460^{*}$ & $-.484^{*}$ & \\
Intell. & $-.013 \dagger$ & $-.015^{*}$ & $-.118^{*}$ & $-.157^{*}$ & $-.117^{*}$ & $-.060^{*}$ \\
\hline
\end{tabular}

${ }^{\mathrm{a}}$ Before reversing; $\dagger p<.01 ; * p<.001$ 
Table 2. The item $\times$ intelligence interaction effect on the other items. Item 5 (marked grey)

is reversed. All interactions are highly significant $(p<1 \mathrm{e}-23)$.

\begin{tabular}{|c|c|c|c|c|c|c|}
\hline \multirow[b]{2}{*}{ Predictor } & \multicolumn{6}{|c|}{ Outcome } \\
\hline & item 1 & item 2 & item 3 & item 4 & item 5 & item 6 \\
\hline item $1 \times \mathrm{IQ}$ & - & $9.42 \mathrm{e}-02$ & $6.40 \mathrm{e}-02$ & $8.49 \mathrm{e}-02$ & $-1.60 \mathrm{e}-01$ & $9.71 \mathrm{e}-02$ \\
\hline & 7.80e-02 & - & $6.41 \mathrm{e}-02$ & & & \\
\hline$\times \mathrm{IO}$ & & $1.14 \mathrm{e}-01$ & - & $7.92 \mathrm{e}-02$ & -1.58 & $1.01 \mathrm{e}-01$ \\
\hline item $4 \times \mathrm{IQ}$ & $8.11 \mathrm{e}-02$ & $8.53 \mathrm{e}-02$ & $3.69 \mathrm{e}-02$ & - & $-1.42 \mathrm{e}-01$ & $7.89 \mathrm{e}-02$ \\
\hline item $5 \times I Q$ & $-1.46 e-01$ & $-1.31 \mathrm{e}-01$ & $-1.30 \mathrm{e}-01$ & $-1.14 \mathrm{e}-01$ & - & $-1.46 \mathrm{e}-01$ \\
\hline item $6 \times \mathrm{IQ}$ & $7.06 \mathrm{e}-02$ & $7.65 e-02$ & $5.31 \mathrm{e}-02$ & $5.42 \mathrm{e}-02$ & $-1.52 \mathrm{e}-01$ & - \\
\hline
\end{tabular}

the scale (from 1 to 2 , from 2 to 3 , etc.) is treated as a function of the subject's score on the measured dimension and the difficulty of the step in a similar fashion as in Rasch's dichotomous response model above (Masters, 1982). Analyzes were conducted with R 3.5.0 software (R Core Team, 2018) using the psych (Revelle, 2018) and eRm (Mair, Hatzinger, \& Maier, 2018) packages. Data and script are available at https://osf.io/gqush/..

\section{Results}

Descriptive statistics for and correlations between the study variables is presented in Table 1 . We see a negative correlation between all of the items, including item 5 before reversing, and intelligence.

The association between intelligence and response consistency for three different situations is presented in Figure 1. The closeness of the alpha/omega-values when incorrectly including the non-reversed item 5 (dashed line) and when correctly reversing it (solid line), and the difference in alpha/omega between the latter of these situations and when deleting item 5 (dotted line), indicates that persons with the lowest intelligence have problems handling the reversed item. The pattern of alpha/omega-values for those high in intelligence indicates, on the other hand, no problems with this handling. However, we also see a positive association between intelligence and consistency that cannot be explained by the reversed item (dotted line). The stronger association between intelligence and omega compared to alpha when incorrectly including the non-reversed item 5 (dashed line) is probably due to the fact that the latter of these coefficients penalize lack of tau equivalence to a higher degree in combination with a stronger negative association between item 5 and the other items, i.e. a higher degree of non-equivalence, among those with high compared to low intelligence (see below).

Besides item 5, we see a positive association between the items (Table 1). However, a positive (negative for item 5) item $\times$ intelligence interaction effect shows that these associations strengthen with increased intelligence (Table 2, Figure 2), again indicating a positive association between intelligence and consistency. The lack of association between item 3 and item 5 for those with the lowest intelligence (Figure 2) indicates, once again, problems handling the reversed item.

Given the lower reliability among those with low intelligence, we could expect a regression toward the mean among these subjects when including item 5 (correctly reversed) in the scale compared to when leaving it out. This prediction was evaluated using

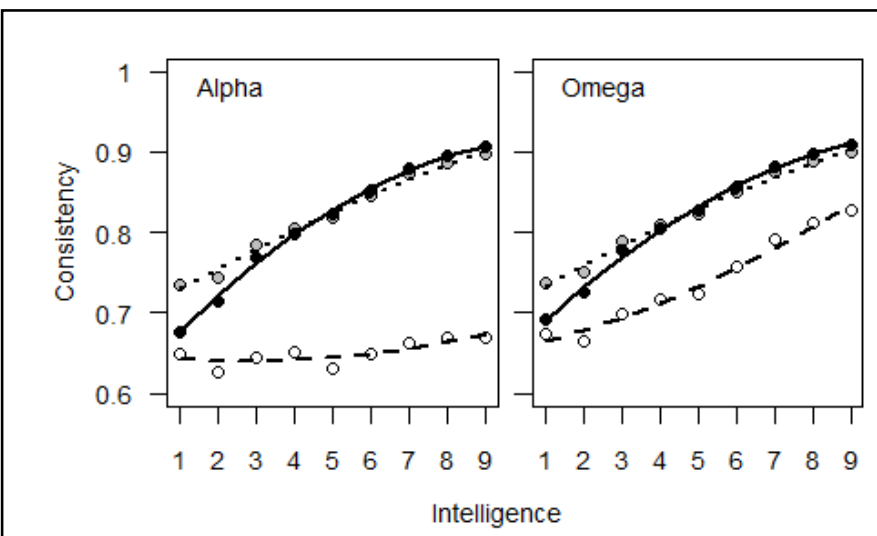

Figure 1. Consistency (coefficients alpha and omega) when incorrectly including item 5 without reversal (white dots, dashed line), when removing item 5 (grey dots, dotted line), and when including item 5 after reversal (black dots, solid line) as functions of intelligence.

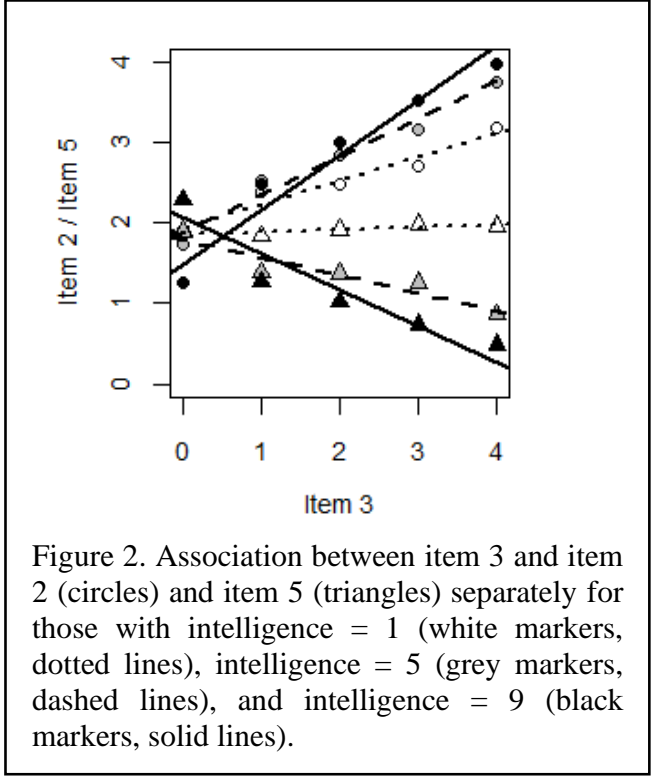


three different ways to calculate the subjects' score on the scale (see the Method section). In all three cases we observe the following (Table 3): (a) Inclusion of item 5 tends to attenuate the scores, so that those above the grand mean get a lower score while those below the grand mean experience an increase. This might explain why the correlation between the scores on the scale and intelligence is stronger when excluding item 5 compared to when it is included; (b) Change in the scale score when including item 5 is largest for those lowest in intelligence.

\section{Discussion}

The present study demonstrates a positive association between intelligence and response consistency, something that could be due to, for example, better working memory capacity and understanding of word meanings among those with higher intelligence. Ralph Waldo Emerson claimed that $(1865, p .58)$ "A foolish consistency is the hobgoblin of little minds". Consequently, the present findings put Emerson in a bit of a dilemma. Holding on to this opinion would, according to his own assertion, be indicative of little-mindedness while non-consistency, according to the present findings, would suggest lack of brilliance. However, we suspect that if given the opportunity to respond, Emerson would probably find a way out of this dilemma and make us look like fools in the process.

The present findings also indicate that reversed items in measurement instruments would tend to have a negative effect on statistical power when analyzing the association between whatever the instrument is measuring and intelligence. This because those low in intelligence experience problems handling reversed items which, due to regression toward the mean, results in a score closer to the scale mean than would otherwise be observed. On the other hand, the presence of reversed items could mitigate bias in the measurement. For example, without any reversed items it would be difficult to know if a high score among those with low intelligence is due to a true endorsement of the opinion in question or an acquiescent response style. A recommendation would be to compare results when including and excluding reversed items in/from the analysis as well as having a look at the individual items. Lechner and Rammstedt (2015) present a way to calculate a scale score adjusted for acquiescence.

With the present conscription data, for example, we would be reluctant to assume any association between intelligence and endorsement of a strong military defense, although we see a negative correlation for three different ways of calculating a scale score, both including and excluding the reversed item (Table 3). This because those low in intelligence tend to score higher on all items, including the reversed item before reversing (Table 1). This indicates that the negative association between intelligence and endorsement of a strong military defense is confounded by a negative association between intelligence and an acquiescent response style, something that has been demonstrated before (Gudjonsson, 1990; Gudjonsson \& Young, 2011; Lechner \& Rammstedt, 2015; Navarro-González et al., 2018).

The present study is limited both by the used sample and instrument. Based on the present study alone, it could be possible that the main finding of a positive association between intelligence and response consistency is something specific to men born in Sweden in the middle of the $19^{\text {th }}$ century who are asked about their endorsement of a strong military defense. However, a similar association has been demonstrated with different instruments among Scottish farmers (Austin et al., 1997), male and female teenage delinquents in Ohio (Pinsoneault, 1998), Estonian (Allik et al., 2004) and Spanish (Navarro-González et al., 2018) adolescents, as well as adult Spanish job applicants (Escorial et al., 2019). Still, it could be informative to investigate if this association can be found with a wider selection of instruments and in additional populations.

Unfortunately, lack of motivation/ carelessness and inadequate reading ability among some subjects are two likely threats against the internal validity of

Table 3. Mean values on the scale measuring endorsement of a strong military defense, calculated in three different ways, when excluding (E5) and including (I5) item 5 (correctly reversed) as well as the difference between these two conditions. For all subjects as well as separately for the nine levels of intelligence.

\begin{tabular}{|c|c|c|c|c|c|c|c|c|c|}
\hline \multirow[b]{2}{*}{ Intell. } & \multicolumn{3}{|c|}{ Mean z-score } & \multicolumn{3}{|c|}{ Factor Score } & \multicolumn{3}{|c|}{ Theta } \\
\hline & E5 & I5 & Diff. & E5 & I5 & Diff. & E5 & I5 & Diff. \\
\hline All & -0.003 & -0.003 & 0.000 & 0.005 & 0.006 & -0.001 & 0.702 & 0.746 & $-0.044 *$ \\
\hline 1 & 0.200 & 0.097 & $0.102 *$ & 0.191 & 0.127 & $0.064 *$ & 0.983 & 0.854 & $0.129 *$ \\
\hline 2 & 0.150 & 0.084 & $0.066^{*}$ & 0.162 & 0.123 & $0.040 *$ & 0.909 & 0.841 & $0.068 *$ \\
\hline 3 & 0.083 & 0.047 & $0.037 *$ & 0.097 & 0.073 & $0.023 *$ & 0.816 & 0.791 & $0.025^{*}$ \\
\hline 4 & 0.047 & 0.033 & $0.013 *$ & 0.062 & 0.056 & $0.008 *$ & 0.764 & 0.775 & $-0.012 *$ \\
\hline 5 & -0.012 & -0.010 & -0.003 & 0.000 & 0.005 & -0.002 & 0.686 & 0.730 & $-0.044 *$ \\
\hline 6 & -0.047 & -0.027 & $-0.020^{*}$ & -0.040 & -0.025 & $-0.012 *$ & 0.632 & 0.709 & $-0.077 *$ \\
\hline 7 & -0.072 & -0.041 & $-0.030^{*}$ & -0.063 & -0.043 & $-0.019 *$ & 0.614 & 0.712 & $-0.098 *$ \\
\hline 8 & -0.066 & -0.038 & $-0.029 *$ & -0.063 & -0.043 & $-0.019 *$ & 0.621 & 0.726 & $-0.105^{*}$ \\
\hline 9 & -0.089 & -0.063 & $-0.026^{*}$ & -0.090 & -0.072 & $-0.014 *$ & 0.611 & 0.717 & $-0.106^{*}$ \\
\hline$r^{a}$ & $-0.090 *$ & $-0.052 *$ & $-0.204 *$ & $-0.080 *$ & $-0.059 *$ & $-0.193^{*}$ & $-0.087^{*}$ & $-0.037 *$ & $-0.222 *$ \\
\hline
\end{tabular}


the study, as these probably would have a negative effect on both the performance on the intelligence test and the response consistency on the items measuring endorsement of a strong military defense, thereby confounding the positive association between these factors. In future studies, the confounding effect of poor reading ability might be diminished by using auditory tests (partly done by Pinsoneault, 1998) and lack of motivation, at least for the intelligence test, by some kind of reward for good performances or an anticipated request to explain one's answers.

\section{References}

Allik, J., Laidra, K., Realo, A., \& Pullmann, H. (2004). Personality development from 12 to 18 years of age: Changes in mean levels and structure of traits. European Journal of Personality, 18, 445-462.

Austin, E. J., Deary, I. J., \& Gibson, G. J. (1997). Relationships between ability and personality: Three hypotheses tested. Intelligence, 25, 49-70.

Brand, C., Egan, V., \& Deary, I. J. (1994). Intelligence, personality, and society: "Constructivist" versus "essentialist" possibilities. In D. K. Detterman (Ed.). Current Topics in Human Intelligence (Volume 4) (pp. 2942). Norwood, NJ: Ablex.

Carlstedt, B. (2000). Cognitive abilities: Aspects of structure, process, and measurement. Gothenburg: ACTA Universitatis Gothoburgensis.

Conijn, J. M., Emons, W. H. M., van Assen, M. A. L. M., Pedersen, S. S., \& Sijtsma, K. (2013). Explanatory, multilevel person-fit analysis of response consistency on the Spielberger State-Trait Anxiety Inventory. Multivariate Behavioral Research, 48, 692-718.

Cronbach, L. J. (1951). Coefficient alpha and the internal structure of tests. Psychometrika, 16, 297-334.

Emerson, R.W. (1865). Essays. Boston, MA: Houghton Mifflin Company.

Escorial, S., Navarro-González, D., Ferrando, P. J., \& VigilColet, A. (2019). Is individual reliability responsible for the differences in personality differentiation across ability levels? Personality and Individual Differences, 139, 331336.

Gudjonsson, G. H. (1990). The relationship of intellectual skills to suggestibility, compliance and acquiescence. Personality and Individual Differences, 11, 227-231.

Gudjonsson, G. H., \& Young, S. (2011). Personality and deception. Are suggestibility, compliance and acquiescence related to socially desirable responding? Personality and Individual Differences, 50, 192-195.

Guttman, L. (1945). A basis for analyzing test-retest reliability. Psychometrika, 10, 255-282.

Hemmingsson, T., Melin, B., Allebeck, P., \& Lundberg, I. (2006). The association between cognitive ability measured at ages 18-20 and mortality during 30 years of follow-up A prospective observational study among Swedish males born 1949-51. International Journal of Epidemiology, 35, 665-670.

Lechner, C. M., \& Rammstedt, B. (2015). Cognitive ability, acquiescence, and the structure of personality in a sample of older adults. Psychological Assessment, 27, 1301-1311.

Light, C. S., Zax, M., \& Gardiner, D. H. (1965). Relationship of age, sex, and intelligence level to extreme response style. Journal of Personality and Social Psychology, 2, 907-909.

Lord, F. M. \& Novick, R. (1968). Statistical theories of mental test scores. Readings, MA: Addison-Wesley.

Mair, P., Hatzinger, R., \& Maier M. J. (2018). eRm: Extended Rasch modeling. 0.16-2. http://erm.r-forge.r-project.org/

Makowsky, M. D., \& Miller, S. C. (2014). Education, intelligence, and attitude extremity. Public Opinion Quarterly, 78, 832-858.
Masters, G. N. (1982). A Rasch model for partial credit scoring. Psychometrika, 47, 149-174.

McDonald, R. P. (1999). Test theory: A unified treatment. Mahwah, NJ: Lawrence Erlbaum.

McFarland, S. G., \& Sparks, C. M. (1985). Age, education, and the internal consistency of personality scales. Journal of Personality and Social Psychology, 49, 1692-1702.

McNeish, D. (2018). Thanks coefficient alpha, we'll take it from here. Psychological Methods, 23, 412-433.

Meijer, R. R., Egberink, I. J. L., Emons, W. H. H., \& Sijtsma, K. (2008). Detection and validation of unscalable item score patterns using item response theory: An illustration with Harter's Self-Perception Profile for Children. Journal of Personality Assessment, 90, 227-238.

Navarro-González, D., Ferrando, P. J., \& Vigil-Colet, A. (2018) Is general intelligence responsible for differences in individual reliability in personality measures? Personality and Individual Differences, 130, 1-5.

Pinsoneault, T. B. (1998). A variable response inconsistency scale and a true response inconsistency scale for the Jesness Inventory. Psychological Assessment, 10, 21-32.

$\mathrm{R}$ Core Team (2018). R: A language and environment for statistical computing. R Foundation for Statistical Computing, Vienna, Austria. URL https://www.Rproject.org/.

Rasch, G. (1960). Probabilistic models for some intelligence and attainment tests. Copenhagen, Denmark: Danish Institute for Educational Research.

Raykov, T. (1997). Scale reliability, Cronbach's coefficient alpha, and violations of essential tau-equivalence with fixed congeneric components. Multivariate Behavioral Research, 32, 329-353

Reise, S. P., \& Waller, N. G. (1993). Traitedness and the assessment of response pattern scalability. Journal of Personality and Social Psychology, 65, 143-151.

Revelle, W. (2018). psych: Procedures for personality and psychological research. Northwestern University, Evanston, Illinois, USA, https://CRAN.R-project.org/package=psych Version $=1.8 .4$

Revelle, W., \& Zinbarg, R. E. (2009). Coefficients alpha, omega and the glb: Comments on Sijtsma. Psychometrika, 74, 145154.

Ross, A. (1988). De värnpliktigas prestationsförmåga vid inskrivningspövningar i Sverige 1969-1979 [The conscripts' capacity at enlistment testing in Sweden 1969-1979]. Umeå: Umeå Universitet, Pedagogiska Institutionen.

Sijtsma, K. (2009). On the use, the misuse, and the very limited usefulness of Cronbach's alpha. Psychometrika, 74, 107120 .

Wilkinson, A. E. (1970). Relationship between measures of intellectual functioning and extreme response style. Journal of Social Psychology, 81, 271-272.

Zammit, S., Allebeck, P., David, A. S., Dalman, C., Hemmingsson, T., Lundberg, I., \& Lewis, G. (2004). A longitudinal study of premorbid IQ score and risk of developing schizophrenia, bipolar disorder, severe depression, and other nonaffective psychoses. Archives of General Psychiatry, 61, 354-360. 